\title{
Diclofenac plasma protein binding: PK-PD modelling in cardiac patients submitted to cardiopulmonary bypass
}

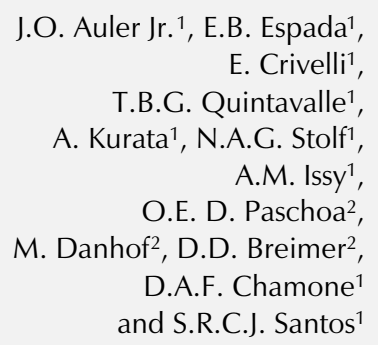

\author{
${ }^{1}$ Laboratório de Pesquisa, Instituto do Coração, Hospital das Clínicas, \\ Faculdade de Medicina, Universidade de São Paulo, 05403-000 São Paulo, SP, Brasil \\ ${ }^{2}$ Center for Drug Research, 2300 RA Leiden, Amsterdam, Holland
}

\section{Correspondence \\ S.R.C.J. Santos \\ Laboratório de Pesquisa \\ Instituto do Coração \\ Hospital das Clínicas, FMUSP \\ Av. Dr. Enéas C. Aguiar, 44 \\ 05403-000 São Paulo, SP \\ Brasil}

Presented at the "Congresso Brasileiro sobre Dor", São Paulo, SP, Brasil, March 15-17, 1996, and at the XI Annual Meeting of the Federação de Sociedades de Biologia Experimental, Caxambu, MG, Brasil, August 21-24, 1996.

Research supported by FAPESP (Nos. 94/2908-7 and 94/2491-9), CNPq-PIBIC/FCFUSP and the Brazilian pharmaceutical industry BIOGALENICA-CIBA GEIGY S.A.

Received April 12, 1996 Accepted January 6, 1997

\begin{abstract}
Twenty-four surgical patients of both sexes without cardiac, hepatic, renal or endocrine dysfunctions were divided into two groups: 10 cardiac surgical patients submitted to myocardial revascularization and cardiopulmonary bypass (CPB), 3 females and 7 males aged $65 \pm$ 11 years, $74 \pm 16 \mathrm{~kg}$ body weight, $166 \pm 9 \mathrm{~cm}$ height and $1.80 \pm 0.21$ $\mathrm{m}^{2}$ body surface area (BSA), and control, 14 surgical patients not submitted to CPB, 11 female and 3 males aged $41 \pm 14$ years, $66 \pm 14$ $\mathrm{kg}$ body weight, $159 \pm 9 \mathrm{~cm}$ height and $1.65 \pm 0.16 \mathrm{~m}^{2} \mathrm{BSA}$ (mean \pm SD). Sodium diclofenac $\left(1 \mathrm{mg} / \mathrm{kg}\right.$, im Voltaren $75^{\circledR}$ twice a day) was administered to patients in the Recovery Unit $48 \mathrm{~h}$ after surgery. Venous blood samples were collected during a period of $0-12 \mathrm{~h}$ and analgesia was measure by the visual analogue scale (VAS) during the same period. Plasma diclofenac levels were measured by high performance liquid chromatography. A two-compartment open model was applied to obtain the plasma decay curve and to estimate kinetic parameters. Plasma diclofenac protein binding decreased whereas free plasma diclofenac levels were increased five-fold in CPB patients. Data obtained for analgesia reported as the maximum effect ( $\left.\mathrm{E}_{\mathrm{MAX}}\right)$ were: $25 \%$ VAS (CPB) vs 10\% VAS (control), P<0.05, median measured by the visual analogue scale where $100 \%$ is equivalent to the highest level of pain. To correlate the effect versus plasma diclofenac levels, the $\mathrm{E}_{\mathrm{MAX}}$ sigmoid model was applied. A prolongation of the

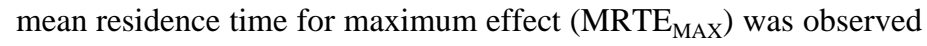
without any change in lag-time in CPB in spite of the reduced analgesia reported for these patients, during the time-dose interval. In conclusion, the extent of plasma diclofenac protein binding was influenced by CPB with clinically relevant kinetic-dynamic consequences.
\end{abstract}

Key words

- Diclofenac

- Plasma protein binding

- Cardiopulmonary bypass

- Kinetic-dynamic parameters

- Analgesia

- Visual analogue scale 
Diclofenac is a nonsteroidal anti-inflammatory drug (NSAID) widely prescribed as sodium or potassium salt for chronic pain (1). Diclofenac is prescribed for the relief of chronic or acute pain, by oral ( $p o$ ) or intramuscular (im) administration, respectively. After cardiac, open heart or abdominal surgery, diclofenac administered im during the postoperative period is absorbed rapidly. As this drug shows a high percentage of plasma protein binding, its elimination through the hepatic metabolism (hydroxylation followed by glucuronidation, phases 1 and 2 of drug metabolism) and urinary excretion are mainly dependent on the plasma concentration of the free drug. A low percentage of the drug is glucuronated directly and excreted in the bile $(2,3)$.

In cardiac surgery, loss of blood, high mobilization of liquids and cardiopulmonary bypass $(\mathrm{CPB})$ with hemodynamic consequences such as hypothermia and hemodilution occur (4). During the postoperative period of cardiac surgery with cardiopulmonary bypass, there is a $30 \%$ reduction of hepatic blood flow accompanied by changes in the metabolism of diclofenac $(4,5)$. The aim of the present study was to measure the pharmacokinetics and pharmacodynamics of diclofenac on the basis of plasma protein binding, during the postoperative period in surgical patients submitted or not to cardiopulmonary bypass.

Twenty-four surgical patients of both sexes were investigated in a protocol controlled study which was approved by the Local Ethics Committee of the Hospital. Patients selected for this study were divided into two groups: Group I - 10 patients submitted to cardiac surgery with $\mathrm{CPB}, 65 \pm 11$ years, $74 \pm 16 \mathrm{~kg}, 166 \pm 9 \mathrm{~cm}$ height and 1.80 $\pm 0.21 \mathrm{~m}^{2}$ body surface area (BSA), mean \pm SD. Group II - 14 patients, $41 \pm 14$ years, 66 $\pm 14 \mathrm{~kg}, 159 \pm 9 \mathrm{~cm}$ height and $1.65 \pm 0.16$ $\mathrm{m}^{2}$ BSA, submitted to cholecystectomy, incisional hernioplasty, gastroplasty and gastrectomy without cardiopulmonary bypass (control). The patients evaluated here showed normal renal, liver, and endocrine functions as well as biotransformation of drugs and absence of heart failure. Biotransformation of drugs in general was evaluated by the antipyrine test (6). The conventional antipyrine test associated with oxidative and conjugation capacities using 3-hydroxyantipyrine (HMA) + 4-hydroxyantipyrine (4HA) + norantipyrine (NORA) or 3-hydroxyantipyrine as free or glucuronide forms, respectively, was applied to measure the activity of cytochrome $\mathrm{P}_{450}$ subfamilies I, II, and III in the patients studied. Patients with gastric disturbances, allergy or evolution to renal failure were excluded from the study. All patients gave informed written consent to participate in the study.

The study protocol consisted of two phases. Phase I - selection by clinical and laboratory routine evaluation of all patients during the preoperative period. Phase II sodium diclofenac, $1 \mathrm{mg} / \mathrm{kg}$, im, Voltaren $75^{\circledR}$ twice daily was administered to patients in the Recovery Unit $48 \mathrm{~h}$ after surgery. Venous blood samples were collected during the time-dose interval (0-12 h). Analgesia was measured by the visual analogue scale (VAS) and reported as percentage of pain intensity during the same period, ranging from zero (none) to $100 \%$ (maximum pain that each patient could tolerate) (7). Plasma diclofenac levels (as bounded or free drug) were determined by a micromethod after an ultrafiltration procedure followed by HPLC as described previously by the same authors for total or free drug, respectively (8-10).

For the pharmacokinetic evaluation, a two-compartment open model was applied to obtain the decay curve for plasma diclofenac, $\log \mathrm{C}$ vs time. The kinetic parameters listed in Table 1, i.e., systemic bioavailability: area under the curve $\left(\mathrm{AUC}_{\mathrm{T}}\right)$, drug elimination: total body clearance $\left(\mathrm{Cl}_{\mathrm{T}}\right)$, drug distribution: volume of distribution $\left(\mathrm{Vd}_{\mathrm{AREA}}\right)$, halflife and rate constants, were estimated (11). 
Diclofenac plasma protein binding was determined for both groups of patients after an ultrafiltration technique followed by the clean-up of only $200 \mu \mathrm{l}$ of plasma samples using a single extraction with organic solvent in an acidic medium and HPLC was monitored by absorbance at $254 \mathrm{~nm}$ (9). The sigmoidal maximun effect $\left(\mathrm{E}_{\mathrm{MAX}}\right)$ model was applied to correlate plasma diclofenac data and analgesia measured by the visual analogue scale for each patient (11-13).

The STATGRAPHICS software was applied to the data obtained in the present study. Chi-square, Spearman, Wilcoxon, Mann-Whitney and rank sum tests for paired and unpaired data were used for statistical analysis. Data are reported as median and $\mathrm{P}<0.05$ was considered to be statistically significant (14).

Systemic bioavailability of diclofenac based on $\mathrm{AUC}_{\mathrm{T}}$, rate of bioavailability (RBA), maximum or peak plasma concentration $\left(\mathrm{C}_{\mathrm{MAX}}\right)$ and time to reach the peak plasma concentration ( $\mathrm{T}_{\mathrm{MAX}}$ ) showed similar results for both groups. A rapid absorption was obtained for both groups based on higher plasma concentrations at $0.5 \mathrm{~h}$ of dose administration. A good level of systemic bioavailability was reached for both groups of patients (Table 1 and Figure 1).

A large interindividual variation in drug distribution was shown for both groups, which was measured by alpha $(\alpha)$, a hybrid rate constant, and the distribution rate microconstants $\mathrm{K}_{12}, \mathrm{~K}_{21}$, i.e., drug distribution from central to peripheral compartments or blood-tissue drug distribution and tissueblood drug distribution, respectively. Only the parameter $\mathrm{Vd}_{\mathrm{AREA}}$, i.e., drug distribution in the extravascular fluid compartment, showed a significant difference between groups (50\% reduction: $0.51 \mathrm{l} / \mathrm{kg}$ (CPB) vs $0.981 / \mathrm{kg}$ (control)) (Table 1).

The present results indicate changes in diclofenac distribution not only as a consequence of plasma protein drug binding reduced in patients submitted to cardiopulmo- nary bypass but also due to changes in plasma volume or in fluid compartments. Therefore, volume of distribution and percentage of protein drug binding were the best parameters to indicate changes in drug distribution with consequences of relevance considering analgesia measured by $\mathrm{E}_{\mathrm{MAX}}$, time to reach $\mathrm{E}_{\mathrm{MAX}}\left(\mathrm{TE}_{\mathrm{MAX}}\right)$ and mean residence time for maximum effect (MRTE $\mathrm{MAX}_{\mathrm{MA}}$ ).

Drug elimination was measured by the following parameters: elimination rate constant $(\beta)$, elimination half-life $\left(\mathrm{t}_{(1 / 2) \beta}\right)$ and $\mathrm{Cl}_{\mathrm{T}}$. The data obtained indicate that elimination rate constant was increased by $30 \%$ with a consequent reduction of elimination halflife in CPB.

Total body clearance remained unchanged

Table 1 - Effect of cardiopulmonary bypass (CPB) on systemic bioavailability, distribution and elimination of diclofenac.

Data are reported as medians for $10 \mathrm{CPB}$ patients who received $1 \mathrm{mg} / \mathrm{kg}$ diclofenac, im. $\mathrm{C}_{\mathrm{MAX}}$ : Peak plasma concentration; $\mathrm{T}_{\mathrm{MAX}}$ : time to reach $\mathrm{C}_{\mathrm{MAX}}$; $A \cup C_{T}$ : area under the curve related to systemic availability of drug; RBA: rate of bioavailability; $\alpha$ and $B$ : hybrid distribution and elimination rate constants; $\mathrm{K}_{12}$ and $\mathrm{K}_{21}$ : distribution microconstants; binding: percentage of plasma drug bound to protein; $V d_{\text {AREA }}$ : distribution volume; $t_{(1 / 2) 13}$ : elimination half-life; $\mathrm{Cl}_{\mathrm{T}}$ : plasma clearance; ${ }^{*} \mathrm{P}<0.05 \mathrm{com}$ pared to control (Wilcoxon test, Mann-Whitney test and rank sum test).

\begin{tabular}{|c|c|c|}
\hline Parameters & $\begin{array}{c}\mathrm{CPB} \\
\mathrm{N}=10\end{array}$ & $\begin{array}{l}\text { Control } \\
N=14\end{array}$ \\
\hline \multicolumn{3}{|l|}{ Systemic bioavailability } \\
\hline $\mathrm{C}_{\mathrm{MAX}}(\mathrm{ng} / \mathrm{ml})$ & 2167 & 1811 \\
\hline $\mathrm{T}_{\text {MAX }}(\mathrm{h})$ & 0.50 & 0.50 \\
\hline$A \cup C_{T}\left(\mu \mathrm{g} \mathrm{h}^{-1} \mathrm{ml}^{-1}\right)$ & 4.44 & 4.04 \\
\hline $\operatorname{RBA}\left(\mathrm{h}^{-1}\right)$ & 4.62 & 5.20 \\
\hline \multicolumn{3}{|l|}{ Distribution } \\
\hline$\alpha\left(h^{-1}\right)$ & 2.15 & 1.98 \\
\hline$K_{12}\left(h^{-1}\right)$ & 0.49 & 0.70 \\
\hline$K_{21}\left(h^{-1}\right)$ & 0.65 & 0.82 \\
\hline Binding (\%) & $94^{*}$ & 99 \\
\hline$V d_{A R E A}(1 / k g)$ & $0.51 *$ & 0.98 \\
\hline \multicolumn{3}{|l|}{ Elimination } \\
\hline$B\left(h^{-1}\right)$ & $0.39 *$ & 0.30 \\
\hline$t_{(1 / 2) ß}(h)$ & $1.80^{*}$ & 2.33 \\
\hline $\mathrm{Cl}_{\top}\left(\mathrm{ml} \mathrm{min} \mathrm{m}^{-1} \mathrm{~kg}^{-1}\right)$ & 3.50 & 5.03 \\
\hline
\end{tabular}


A

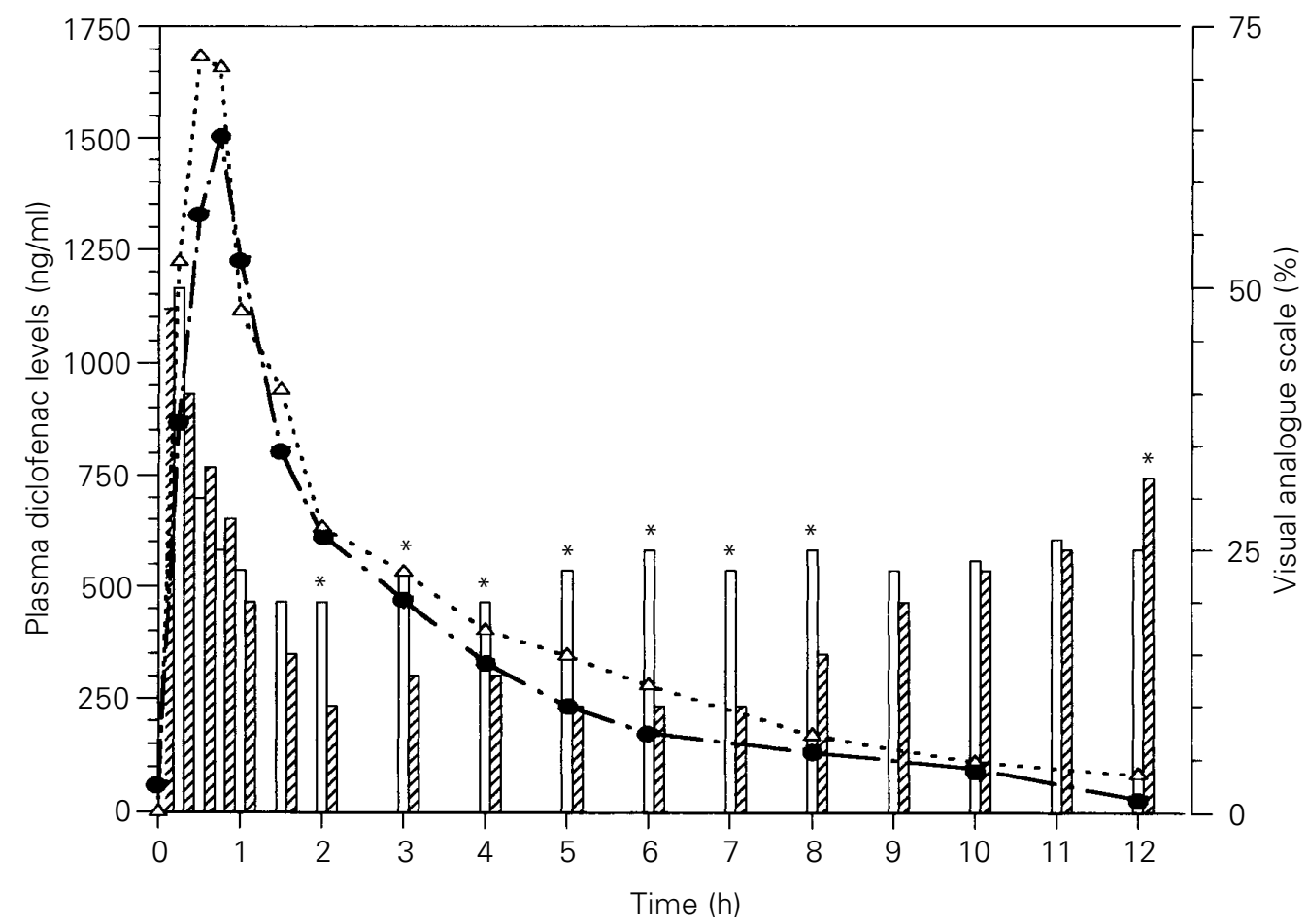

B: Visual analogue scale

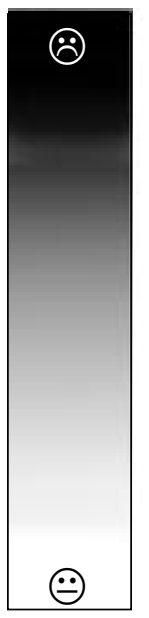

Patient scale

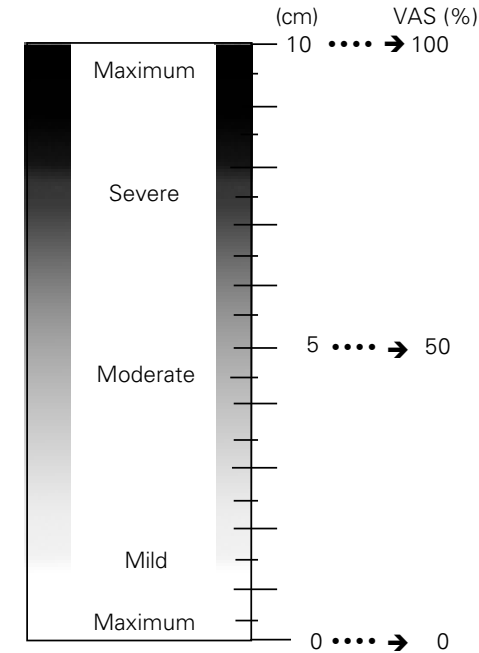

Clinical scale

Figure 1 - Effect of cardiopulmonary bypass (CPB) on plasma diclofenac levels and analgesia. Patients received diclofenac $(1 \mathrm{mg} / \mathrm{kg}, \mathrm{im}$ ) after surgery. $A$, Left ordinate: $\Delta$, plasma diclofenac levels of the CPB group ( $\mathrm{N}=10$ ); plasma diclofenac levels of the control surgical group $(N=14)$. Right ordinate: analgesia measured with the visual analogue scale (see panel B for the explanation). $\square$, Pain level of the CPB group; $\boldsymbol{\square}$, pain level of the control surgical group. ${ }^{*} \mathrm{P}<0.05$ compared to control for analgesia (Wilcoxon test). All data are reported as median values. 
for both groups of patients in spite of a $30 \%$ reduction in hepatic blood flow as reported previously $(4,5)$. The present data showed wide interindividual variation for both groups when expressed as median: $3.50 \mathrm{CPB} v s$ $5.03 \mathrm{ml} \mathrm{min}^{-1} \mathrm{~kg}^{-1}$ control, $\mathrm{P}=0.13$ (Table 1), or as range of variation IC95\%: $2.91-4.43 \mathrm{ml}$ $\min ^{-1} \mathrm{~kg}^{-1}(\mathrm{CPB})$ and $3.32-6.03 \mathrm{ml} \mathrm{min}{ }^{-1} \mathrm{~kg}^{-1}$ (control) $(\mathrm{P}>0.05)$.

Patients from the Recovery Unit investigated in the study protocol showed different reductions in pain after drug administration, measured by the visual analogue scale (7), for which VAS $=0 \%$ means no pain, and $\mathrm{VAS}=100 \%$ means the highest level of pain that each patient could tolerate. Pain was measured in two different situations: rest and cough during the 0-12-h interval. Considering the cough situation, pain was reduced from 55\% to 30\% VAS for CPB and from $50 \%$ to $35 \%$ VAS for control, $0.5 \mathrm{~h}$ after drug administration (Figure 1).

The maximum effect was reached at $2 \mathrm{~h}$ after drug administration. $\mathrm{E}_{\mathrm{MAX}}: \mathrm{TE}_{\mathrm{MAX}}$ measured in patients after cardiopulmonary bypass was 25\% VAS vs 10\% VAS (control), indicating a lower reduction in pain intensity obtained for CPB patients when compared to control.

Analgesia remained unchanged at about $25 \%$ VAS between 0.75 and $12 \mathrm{~h}$ after drug administration for CPB, and at about $10 \%$ VAS for control, during the 2-7-h interval $\left(\mathrm{MRTE}_{\mathrm{MAX}}\right)$, i.e., the period of time that the maximum effect remains constant after drug administration. Then, pain recorded at 8,10 and $12 \mathrm{~h}$ after drug administration increased by $15 \%, 23 \%$ and $32 \%$ VAS, respectively, for the control, while pain remained unchanged (25\% VAS) for $\mathrm{CPB}$ during the same period.
Finally, after drug administration, a lower reduction in pain was obtained for patients after CPB when compared to the control, $55 \%$ to $25 \%$ VAS vs $50 \%$ to $10 \%$ VAS, $\mathrm{P}<0.05$, respectively. A lower analgesia without any change in lag-time was obtained for $\mathrm{CPB}$ when compared to control, probably as a consequence of the reduction in volume of distribution and the increase in free plasma diclofenac levels after cardiopulmonary bypass.

Since diclofenac is extensively metabolized by the liver, followed by urinary excretion of several hydroxylated metabolites, the present data suggest a close relationship between elimination rate constant and diclofenac plasma protein binding. Therefore, the estimated kinetic parameters could explain the direct correlation of analgesia with volume of distribution, and the inverse correlation of analgesia with the diclofenac elimination rate constant. Finally, the kinetic evidence reported here could explain the differences in analgesia between the two groups and the higher pain intensity in CPB patients during the period of $0-12 \mathrm{~h}$ after drug administration. In conclusion, the extent of diclofenac plasma protein binding was influenced by the cardiopulmonary bypass procedure with kinetic-dynamic consequences of clinical relevance.

\section{Acknowledgments}

We acknowledge the Brazilian Society for the Study of Pain and the Carlo Erba Pharmaceutical Industry for the "Professor Sérgio Ferreira Prize”, March 17, 1996. 


\section{References}

1. Raja SN, Meyer RA \& Campbell JN (1988). Peripheral mechanisms of somatic pain. Anesthesiology, 68: 571-590.

2. Degen PH, Dieterle W, Schneider W, Theobald W \& Sinterhauf U (1988). Pharmacokinetics of diclofenac and five metabolites after single doses in healthy volunteers and after repeated doses in patients. Xenobiotica, 18: 1449-1455.

3. Riess W, Stierlin H, Degen P, Faigle JW, Gérardin A, Moppert J, Sallmann A, Schmid K, Schweizer A, Sule M, Theobald W \& Wagner J (1978). Pharmacokinetics and metabolism of the anti-inflammatory agent Voltaren. Scandinavian Journal of Rheumatology, 22 (Suppl): 17-29.

4. Holley FO, Ponganis KV \& Stansky DR (1982). Effect of cardiopulmonary bypass on the pharmacokinetics of drugs. Clinical Pharmacokinetics, 7: 234-251.
5. Menassé R, Hendwall J, Kraetz J, Pericin L, Riesterer L, Sallmann A, Ziel R \& Jaques $R$ (1978). Pharmacological properties of diclofenac sodium and its metabolites. Scandinavian Journal of Rheumatology, 22 (Suppl): 5-16.

6. Lanchote VL, Donzella H, Chamone DAF \& Santos SRCJ (1996). A simplified assay using high-performance liquid chromatography for the simultaneous determination of antipyrine and its three major metabolites in urine: a drug metabolism study. Revista de Farmácia e Bioquímica, 32 (in press).

7. Scott J \& Huskisson EC (1976). Graphic representation of pain. Pain, 2: 176-184.

8. Rosenkranz H, Schlossmann K \& Scholtan W (1974). Die Bindung von 4-(2'-nitrophenyl-1,4-dihydropyridin-3,5-dicarbonsäuredimethylester (Nifedipine) sowie von anderen koronarwirksamen Stoffen an die Eiweißkörper des Serums. Arzneimittelforschung, 24: 455-466.
9. Santos SRCJ, Donzella H, Bertoline MA, Pereira MD, Omosako CEK \& Porta V (1992). Simplified micromethod for the HPLC measurement of diclofenac in plasma. Brazilian Journal of Medical and Biological Research, 25: 125-128.

10. Santos SRCJ (1982). Nova técnica analítica para estudo farmacocinético da nifedipina. Doctoral thesis, USP, São Paulo.

11. Ritschel WA (1986). Handbook of Pharmacokinetics. 3rd edn. Drug Intelligence Publications, Bethesda.

12. Holford NHG \& Sheiner LB (1981). Understanding the dose-effect relationship: clinical application of pharmacokineticpharmacodynamic models. Clinical Pharmacokinetics, 6: 429-453.

13. Shargel L \& Yu ABC (1991). Applied Biopharmaceutics and Pharmacokinetics. $3 r d$ edn. Prentice-Hall International, London, 465-491.

14. Sachs L (1984). Applied Statistics. 2nd edn. Springer, New York. 